\title{
Correction to: Spatial variation in aquatic invertebrate and riparian songbird mercury exposure across a river-reservoir system with a legacy of mercury contamination
}

\author{
Allyson K. Jackson $\mathbb{D}^{1,2} \cdot$ Collin A. Eagles-Smith ${ }^{3} \cdot$ Colleen Emery $^{3}$
}

Published online: 9 September 2019

(c) Springer Science+Business Media, LLC, part of Springer Nature 2019

\section{Correction to: Ecotoxicology}

https://doi.org/10.1007/s10646-019-02043-z
The original article has been published with the incorrect Fig. 4. The correct Fig. 4 is presented along with this article.

The original article can be found online at https://doi.org/10.1007/ s10646-019-02043-z.

\footnotetext{
Allyson K. Jackson

allyson.jackson@purchase.edu

1 Department of Environmental Studies, Purchase College SUNY, 735 Anderson Hill Road, Purchase, NY 10577, USA

2 Department of Fisheries and Wildlife, Oregon State University, 104 Nash Hall, Corvallis, OR 97331, USA

3 U.S. Geological Survey, Forest and Rangeland Ecosystem Science Center, 3200 SW Jefferson Way, Corvallis, OR 97331, USA
} 

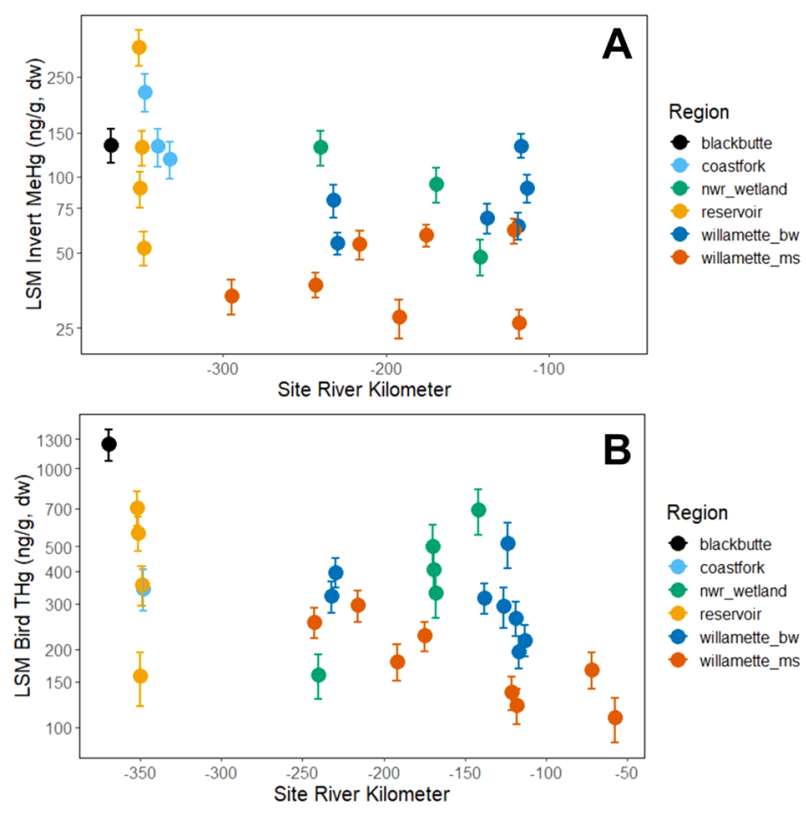

Fig. 4 